\title{
A Study of the Concept of Iranian Traditional Architecture in Bazaars and Shopping Centres
}

\author{
"Nasibeh Sadafi and Maliheh Sharifi
}

\begin{abstract}
Published online: 25 January 2019
To cite this article: Nasibeh Sadafi and Maliheh Sharifi (2018). A study of the concept of Iranian traditional architecture in bazaars and shopping centres. Journal of Construction in Developing Countries, 23(2): 151-165. https://doi.org/10.21315/ jcdc2018.23.2.9.
\end{abstract}

To link to this article: https://doi.org/10.21315/jcdc2018.23.2.9

\begin{abstract}
Technological innovations have changed traditional cities and thrown up new industrial spaces in unforeseen locations. Bazaars or business complexes were among the most important parts of city spaces, and always had great impact on people's lives and their architecture. Due to the expansion of cities, the concept of bazaar has changed, and is replaced by distributed spaces called shopping centres. This study was based on examining the problems and the shortcomings of today's bazaars from the perspective of clients and users and providing solutions to improve practical conditions. To this end, the descriptiveanalytic survey was conducted in Tehran, and 272 questionnaires were distributed and collected randomly among visitors in four shopping malls. To scrutinise the hypothesis, the correlation tests, single variable $T$-test, and F-test were applied. The results from assessments using SPSS16 software showed that the mere external similarity between an environment and form of an element or meaning cannot represent the properties of desired principles for citizens. Therefore, during the design stage, it is necessary to pay enough attention not only to the concepts of a physical form, but also to the mental picture and psychological aspects that audiences receive from an area.
\end{abstract}

Keywords: Traditional architecture, Organic architecture, User satisfaction, Bazaar, Shopping centre

\section{INTRODUCTION}

Iranian traditional architecture is an example of human life's history that has a close relationship with its natural, historical, and human environment (Moradi, KoosheshGaran and Akhtarkavan, 2011). It is also a true response to demands and needs of faith and behaviore of a community. Therefore, it tried to attract the mankind's attention to control the sensual desire, and nurturing heavenly tendencies in human nature (Ekhlas, 2013). According to these special properties, architects and urban planners mostly attempt to preserve and conserve the historical values, as the repeatability of this architecture is difficult.

One of the most distinctive differences of traditional and modern architecture is the attitude of human towards the world and nature (Scott, 2000). In the past, the reciprocal interactions between human and nature was more often. As a result, harmony of the activities with the natural environment and internal content was clearly percievable. This connection was according to operating factors such as considering the effects of time variation, the desire to gain the greatest effects by lowest means and make use of local resources. Figure 1 highlights common criteria

Department of Art and Architecture, Payame Noor University (PNU), Tehran, IRAN

*Corresponding author: nsadafi@gmail.com 
between traditional and organic arcitecture in providing interrelationship between human and the environment. According to the changes in human trends, this relationship has formed in other ways to govern the nature and lost balance and interaction. Therefore, to create an organic architecture that meets the needs of today's society, appropriate undrestanding of the traditional architecture should be translated into the contemporary requirements.

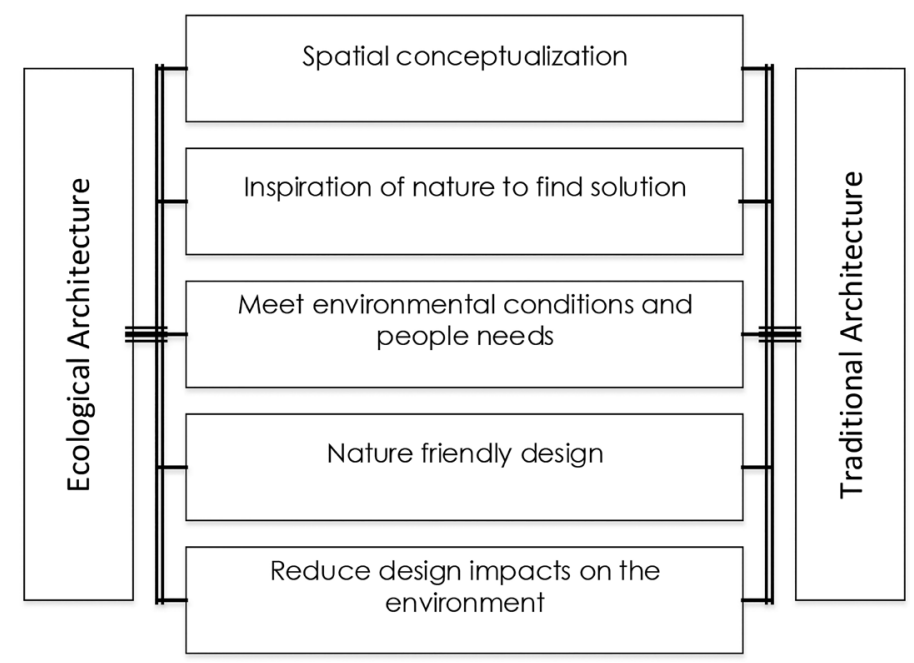

Figure 1. Common Principles of Ecological and Traditional Architecture (Adapted from Nouri [2014])

\section{Bazaar}

In Iranian traditional culture, man was a profoundly social creature that needed interactions with other people. Accordingly, public spaces of the cities were of great importance for city planners. The instances from public areas that have great impacts on architecture and peoples' way of life are bazaars or shopping centres.

Bazaar is an ancient word and used to be pronounced Vachar that has changed over time. The history of the emergence of bazaar and its prevalence in Iran refer to several thousand years before Christ. In some cities during the Parthian and Sassanid, it was one of the important elements of cities. Although, preliminary bazaars were created to fulfill economical needs of the people, soon after, wide social and cultural relations arose and different function such as mosque, religious schools, public bath and palestra were added. It was changed into an urban centre for social, edjucational, and even political activities (Carmona et al., 2003).

A bazaar was always located in the main street of the urban context and connected main entrances of a city. According to its accessability, most of public and govermental buildings were constructed in its vicinity. The main design and development of bazaar in Iranian cities were either organic or planned (Moosavi, 2005). Organic bazaars were developed according to the economical needs of a city in an unplanned manner. However, a planned bazaar was designed logicaly during the economical growth of a city and shaped main streets. The primary structure was shaped as a covered public passway with stores in two sides. 
Mass and open spaces were properly mixed together in bazaars and central courtyards with green spaces to circulate air in interior spaces. Skylights also provided natural light penetration and airfow through interior spaces. For constructing the roof, combination of dome and vault was the typical construction approach. For materials, adobe and sun-dride brick were applied. According to the application of vernacular and environmentall friendly materials, air, land and water pollution were minimised (Assari et al., 2011 ). Figure 2 illustrates the traditional bazaar in Isfahan as an example.
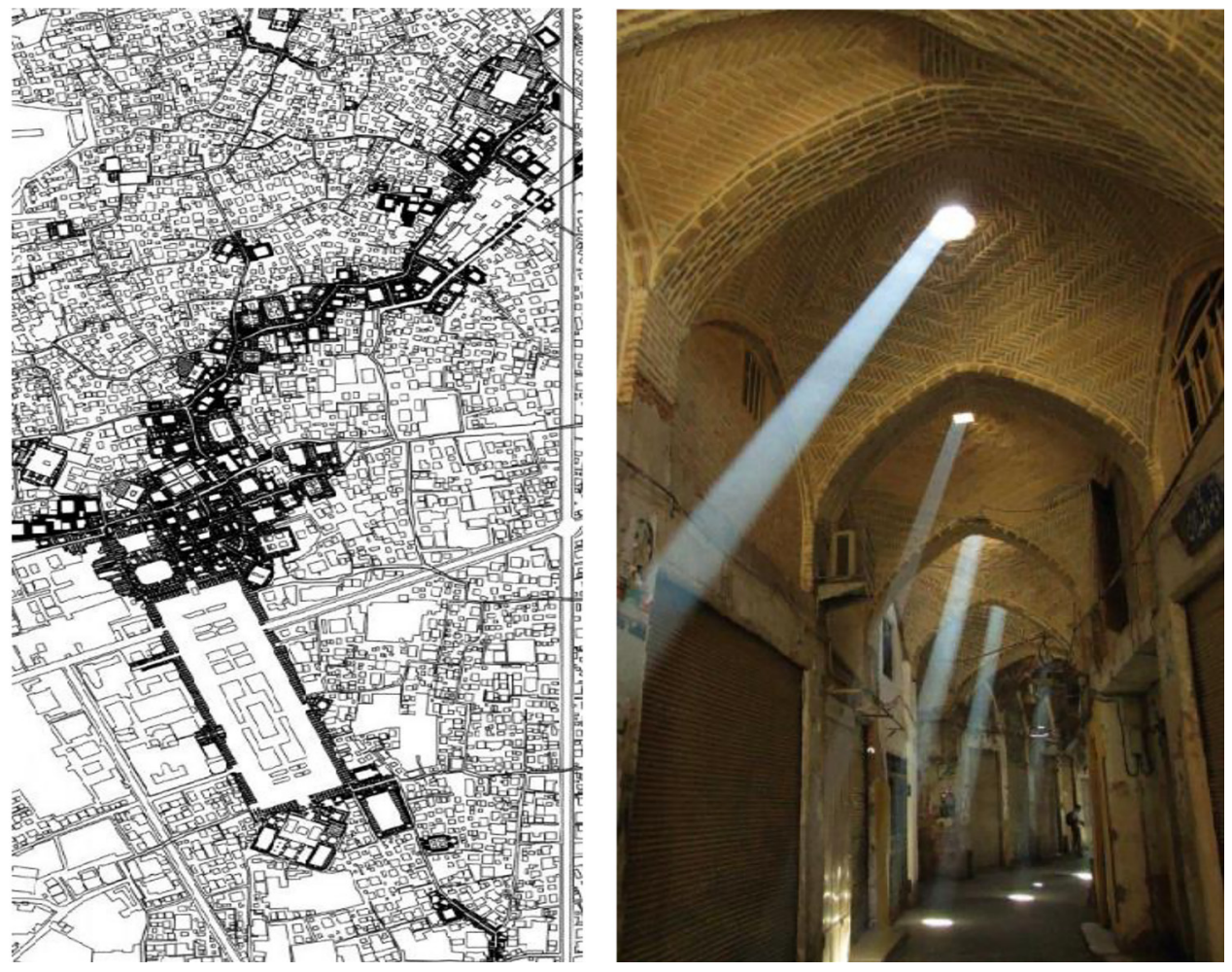

Figure 2. Isfahan Bazaar in the City Context (Source: AoA, 2011)

The economic, cultural, and technological changes due to the industrial revolution and modernism influenced urban environments (Carmona et al., 2003). These transformations occurred very fast in Iranian cities (Ashraf, 2009). The desire for rapid development resulted in transferring the western technology, planning and design to the country. Consequently, many of the recently constructed buildings are copied from western cases that were designed for different culture and tradition (Moradi and Akhtarkavan, 2008).

To meet the requirements of current construction and exploit the facilities of modern technologies, contemporary architecture can take three different directions. First method is to disregard the traditional culture and construction, and recreate the western architecture. Second approach is to follow the past superficially and create inappropriate combinations such as traditional facades 
made of arches and domes with modern high-rise buildings. Finally, the third method is to understand the nature of traditional architecture and apply the modern technology for manifesting this nature. This approach can develop designs with regional identity, environmental conservation and relevance to the principles of traditional architecture.

According to the increasing usage and physical representation of shopping complexes in Iranian cities, the process of planning and designing of these economic, cultural and recreational centres are very important.

Here are the objectives of this study:

1. To clarify the problems and the shortcomings of today's bazaars and shopping centres from the clients and users' point of view.

2. To provide practical solutions to improve the current conditions of shopping centres according to the principles of the traditional architecture.

\section{RELATED WORKS}

Numerous studies considered the relationship between human and nature, and the necessity of organic architecture. This architecture, considers the spirit of space and tries to build it as a part of the natural environment (it should not be imposed). In general, organic architecture has a harmony with the meaning of the perceptible world and nature. In other words, it is a way of thinking that considers the whole existence with their nature in order to put every elements in their place (Falahat and Shahidi, 2003). Mohammadi (2009) has considered the relationship between human and nature using the existing approaches such as: local wisdom, lifestyle, location, structure, order, origin, and organisms as the reasons of reviving. According to the results from this study, the perception of the architectural space and recognising the defined criteria will provide a context for the qualification of these approaches. Nezhad et al. (2012) examined the correct modeling from nature as an aesthetic approach. They listed the beauty of nature inherently and realistically.

Iranian traditional architecture is also considered as an organic architecture, because similar to natural systems the operating factors in this architecture are in terms of the desire to obtain greatest effects from the minimum elements, time, and gradual evolutions (Moradchelleh, 2011). Traditional architecture relied on selfvalues and learning from the existing methods (Azad, 2006: 36). In a research on sustainable architecture, Golan (1995) showed that vernacular architecture in the Middle East was in accordance with environmental features of the land (Golan, 1995: 37). Ebrahimi and Eslami (1991) studied contemporary architecture from the past decade. In their study, the society is divided into three parts namely traditional, industrial, and networked. While they believe that traditional society has a dynamic atmosphere and it is on the basis of tradition, modern society is static and substanceoriented. Moreover, the networked society has the concurrent and timeless aspects and living is happening in cyberspaces. A survey was carried out to investigate the effects of modern styles on the contemporary architecture (Sanei, 1990). It was highlighted that using traditional patterns and original Iranian architecture in contemporary architecture are ways of improving the current situation. Employing these patterns can be studied from various aspects. In order to benefit from the technology and sustainability, passive systems such as wind towers and cisterns as well as local materials could be harnessed (Parast, 2009). 
To define the concept of bazaar, numerous studies are conducted (Talebian, Atashi and Zadeh, 2010; Falamaki, 2006; Pirniya, 2010; Aryan Far, 2010; Vadihie, 1972; Taqvai, 2007; Saremi and Radmehr, 1997; Dstmal Chiyan, 1999). Each one attempts to rehabilitate it based on patterns and concepts. Sodkhah and Qaleh (2013) studied the evolution of bazaar and how it connects to society as well as a bazaar's isolation. The results indicate that some of the features of traditional bazaars such as continuity, strength, beauty, centrality, etc. can be used as the designing ideas for modern business spaces. It could be perceived that examining the relationship between organic architecture and traditional architecture in entertainment and business complexes are very limited. In this study, the customer's satisfaction from business complexes are evaluated and some solutions are proposed based on the criteria of employing traditional architectural to improve the current condition.

\section{RESEARCH METHODOLOGY}

This study is a descriptive-analytic study, which was conducted in Tehran, Iran. Data collection including field works were conducted through distributing questionnaires among citizens. The samples consisted of 272 participants visiting four major shopping centres (Rey bazaar, Tajrish traditional bazaar, Almas shopping centre, and Tirazheh shopping mall). The samples were selected from four different parts of the city (north, south, east and west) to evaluate various cultures and requirements of the users. Accordingly, two cases were traditional bazaars (Rey and Tajish bazaars) and the other two were modern shopping complexes (Almas shopping centre and Tirazheh shopping mall). The participants were chosen randomly. The questionnaire consisted of three groups of questions. The first group was about the personal information. The next group was related to the principles of Iranian traditional architecture and the concepts of organic architecture in bazaars and business centres. In addition, some questions had been raised as suggestions. To measure the variables, 18 closed-ended questions were prepared depending on a Likert scale of five options for a value of "totally agree" as five and the value of "totally disagree" as one. They were encoded and analysed in the coding of the statistical software of SPSS16. Software analysis was carried out using correlation analysis test, single variable $T$-test and F-test. Descriptive statistics and analytical results are presented in tables and graphs.

In what follows, evaluated shopping centres and bazaars are introduced.

\section{Rey Bazaar}

Rey bazaar is one of the historical trade markets, which is near the northern tomb of Shah Abdul Azim in southern Tehran. It is comprised of two rows that make an intersection in their conjunctions. Traditionally, this place was one of the shopping centres of spices, medicine and commercial goods imported by merchants via the Silk Road. The structure of the bazaar consists of plaster, brick and mud, and it belongs to the Safavid dynasty (about 500 years ago) (Faqani, 2006). 

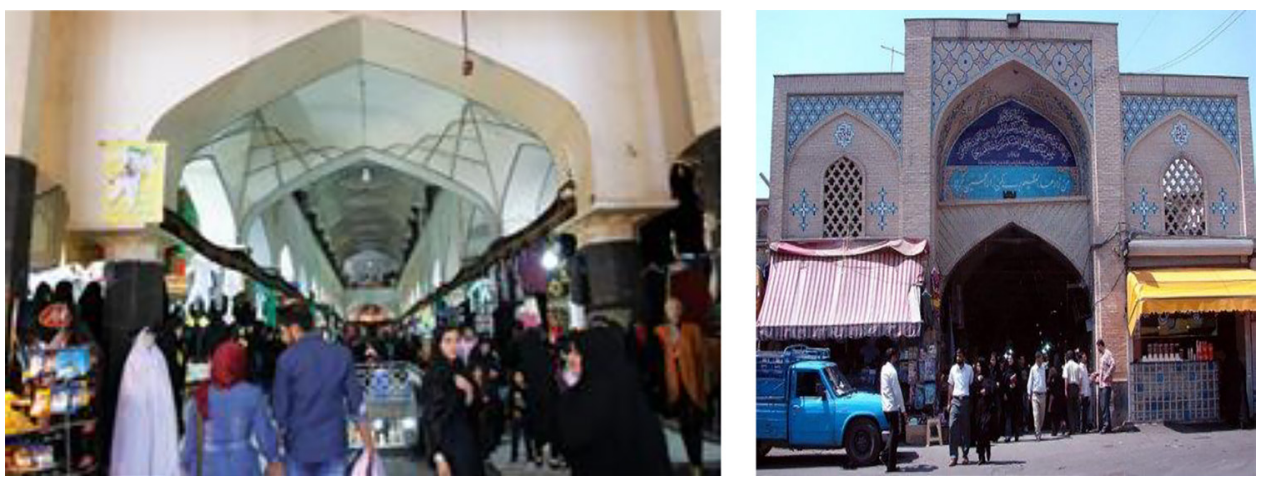

Figure 3. Rey Bazaar, Tehran

\section{Tajrish Traditional Bazaar}

Tajish historical bazaar is a covered place that connects two neighbourhoods, Sar Pol and Tajish. The length of this bazaar is estimated to be approximately 300 to 700 metres, and has more than 400 shops with areas between 12 and 40 sq metres. The bazaar is 150 years old that was built in Qajar dynasty. It is a small sample of Tehran's Grand Bazaar. The shops' names are carved with tiles at their entrances. In addition to the business units, a mosque and a religious site are constituent elements of this bazaar. A part of the beauty of the bazaar is owing to the tile and lattice works performed during renovations in the recent years. Reconstruction of the roof and floor also provides easy access for the customers.
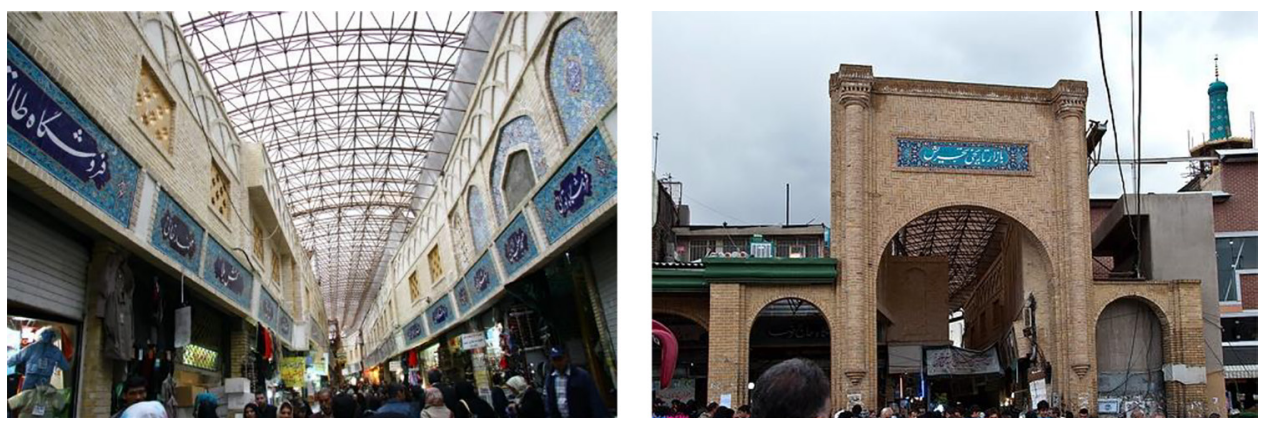

Figure 4. Tajrish Bazaar, Tehran

\section{Almas Shopping Centre}

Almas shopping centre is located in the north-east of Tehran. The complex has a building containing business units and a large courtyard with parking lots. The shopping centre building has a modern architecture. Big business units and wide corridors are among the features of this building. A four-floor retail store with the name Shahrvand is located in this mall with a total of 90 business units. Overall, business units of the complex provide a collection of clothing, accessories, jewellery, beddings, as well as cultural and entertainment products. 

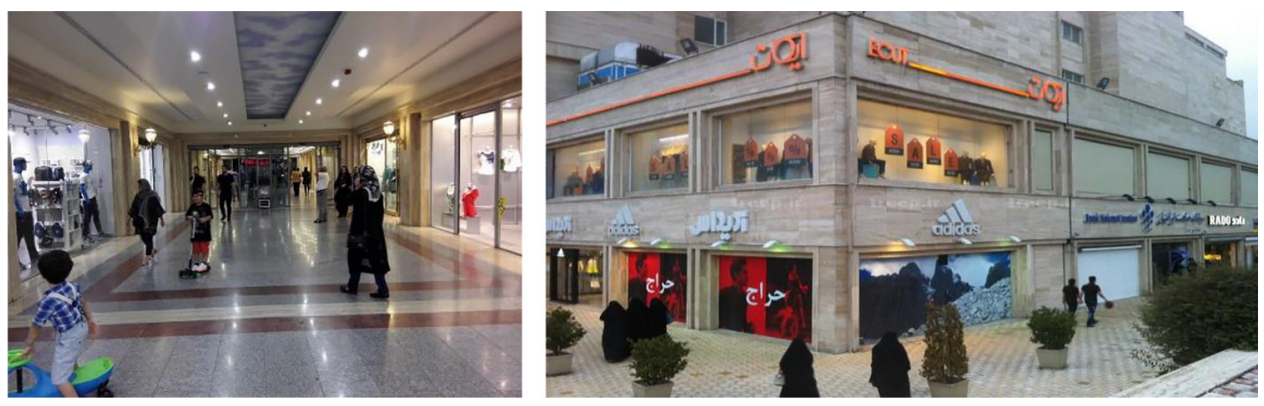

Figure 5. Almas-e-Iran Shopping Centre, Tehran

\section{Tirazheh Shopping Centre}

Tirazheh shopping centre is one of the most famous shopping centres in west Tehran. The centre is located in Ashrafi Esfahani freeway and has a variety of stores. There are also many restaurants in the complex. The most famous unit of this complex is an amusement park, named "Wonderland", which has various modern rides for all ages. One unique feature is the application of natural elements in the interior design of the lobby and corridors.
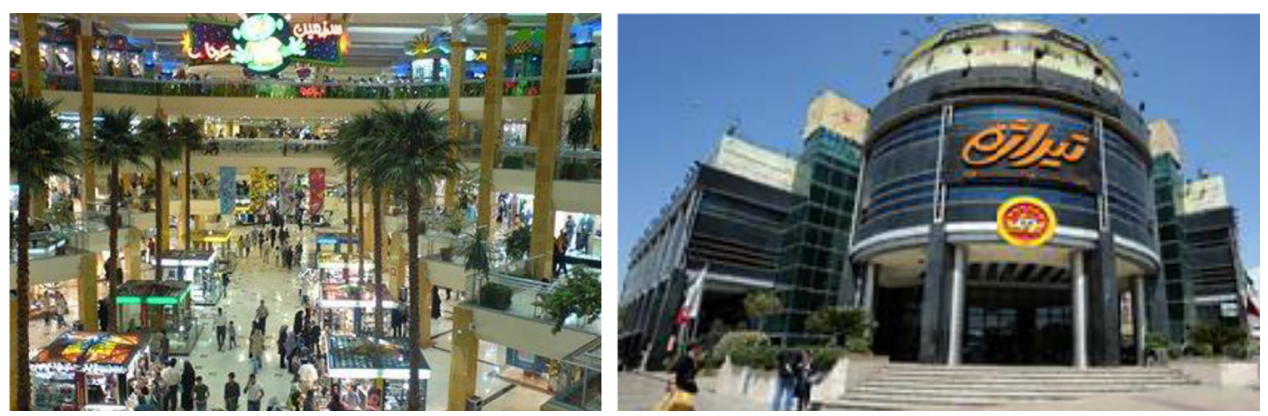

Figure 6. Tirajheh Shopping Centre, Tehran

\section{Data Collection}

Participants in this study consisted of 143 males (52.6\%) and 129 females (47.7\%). In terms of age range, 37 respondents (13.6\%) announced their ages less than 20 years old, $60.3 \%$ between 21 and 35 years old, approximately $21.0 \%$ between 36 and 55 years old and $5.1 \%$ more than 55 years old. The statistics of participants' ages in this study has a clear agreement with the population distribution in Iran. Moreover, from the perspective of frequency of the participants' level of education in the study, $7.4 \%$ of respondents had middle school degree and lower, $38.6 \%$ high school diploma, $11.4 \%$ had associated degree, $32.4 \%$ reported BA/BS and $10.3 \%$ had MA/ MS. 
Nasibeh Sadafi and Maliheh Sharifi
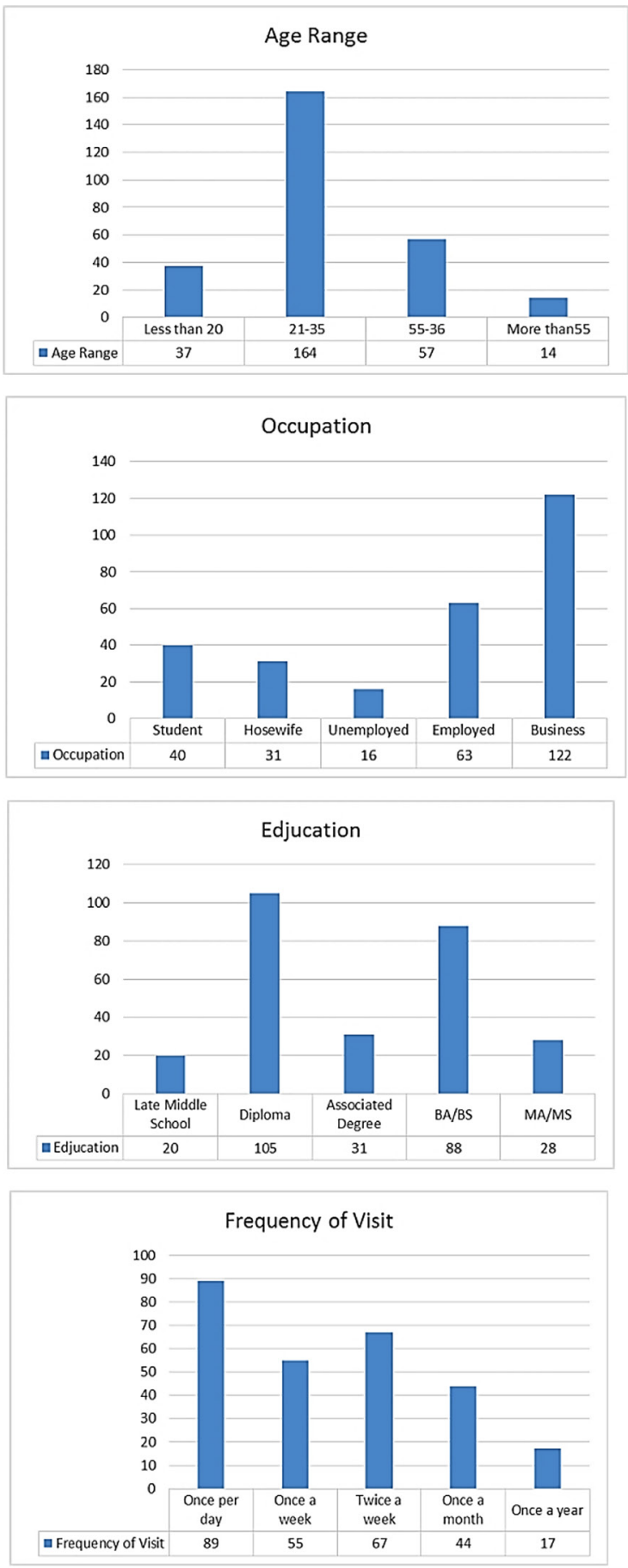

Figure 7. Descriptive Analysis Data 
Distribution of occupation of respondents in this study indicated that 40 persons $(14.7 \%$ of the respondents) were students, $11.4 \%$ were housewives/ husbands, $5.9 \%$ were unemployed, $23.2 \%$ were employed and $44.9 \%$ had their own business. Moreover, in terms of frequency of visiting bazaar, $32.7 \%$ of the respondents announced once per day, $20.2 \%$ said once a week, $16.2 \%$ reported twice a week, $24.6 \%$ once a month and $6.3 \%$ reported once a year (Figure 7 ).

\section{RESULTS AND DISCUSSION}

The questionnaire of this study contains 18 main questions, which are divided into two parts: the common elements between traditional architecture and organicarchitecture and citizens' suggestions that can improve the design in business centres. The results from analysis of variance are presented in the following table.

Table 1. Descriptive Statistics: Measures of Central Tendency and Dispersion of Respondents to the Questionnaire

\begin{tabular}{|c|c|c|c|}
\hline Row & Question & Mean & Variance \\
\hline 1 & $\begin{array}{l}\text { This market is consistent with the urban fabric and the } \\
\text { environment. }\end{array}$ & $2 / 88$ & $1 / 9$ \\
\hline 2 & $\begin{array}{l}\text { There are many spaces of creativity and diversity in building the } \\
\text { spaces in this bazaar. }\end{array}$ & $2 / 78$ & $1 / 21$ \\
\hline 3 & There are multi-function spaces in this bazaar. & $2 / 86$ & $1 / 9$ \\
\hline 4 & The spaces in this bazaar are interconnected and continuous. & $3 / 21$ & $1 / 21$ \\
\hline 5 & $\begin{array}{l}\text { The design of the bazaar is compatible with the users' different } \\
\text { needs. }\end{array}$ & $3 / 15$ & $1 / 19$ \\
\hline 6 & In designing bazaar, repeating a pattern is observable & $3 / 13$ & $1 / 17$ \\
\hline 7 & All available spaces in the bazaar are optimised. & $3 / 13$ & $1 / 43$ \\
\hline 8 & $\begin{array}{l}\text { Appropriate divisions of space and specific details have been } \\
\text { considered. }\end{array}$ & $2 / 77$ & $1 / 21$ \\
\hline \multicolumn{4}{|c|}{ Suggestions: } \\
\hline 9 & I would like to have the outer view in this bazaar. & $3 / 59$ & $1 / 58$ \\
\hline 10 & I prefer construction is combined with the natural environment. & $3 / 41$ & $1 / 34$ \\
\hline 11 & It is better to predict semi-open spaces in the bazaar. & $3 / 49$ & $1 / 34$ \\
\hline 12 & $\begin{array}{l}\text { I prefer the forms and lines of this bazaar to be derived from } \\
\text { natural elements. }\end{array}$ & $3 / 58$ & $1 / 25$ \\
\hline 13 & I prefer traditional indoor bazaars to this bazaar. & $3 / 4$ & $2 / 14$ \\
\hline 14 & $\begin{array}{l}\text { It is better to use elements of water, fountain and brick and } \\
\text { stone in building bazaar. }\end{array}$ & $3 / 72$ & $1 / 14$ \\
\hline 15 & $\begin{array}{l}\text { I would like natural lighting to be used more in designing the } \\
\text { bazaar. }\end{array}$ & $4 / 7$ & $1 / 14$ \\
\hline 16 & $\begin{array}{l}\text { I would like the geometry of Iranian architecture to be used } \\
\text { more in the construction the bazaar. }\end{array}$ & $3 / 80$ & $1 / 58$ \\
\hline 17 & $\begin{array}{l}\text { In designing a bazaar, I want a symmetric and specific central } \\
\text { space. }\end{array}$ & $3 / 62$ & $1 / 19$ \\
\hline 18 & $\begin{array}{l}\text { It is preferred to use recyclable materials in construction of this } \\
\text { bazaar. }\end{array}$ & $4 / 23$ & $1 / 06$ \\
\hline
\end{tabular}


The results show that in the first part of the questionnaire (the measurement of naturalism and traditionalism in the samples), the average score of all the items is low. Moreover, the scores obtained in a few questions is below 3 . This shows that the overall outcome of four case studies did not exactly guide the questionees to the principles in question. In other words, the citizens' opinions indicated that the four studied samples had paid little attention to the principles of nature-oriented architecture and traditional architecture. This, of course, is the result of the opinions of the citizens on both modern complexes (Tirazheh and Almas) and the traditional bazaars (Rey and Tajrish). The general comments of participants in this study indicate that two elements of "consistency and continuity of the space" and "compatibility of bazaar with meeting the needs of individuals" are the most common factors of traditional and nature-oriented architecture. In the participants' points of view, the two components of "repeating perceptible patterns" and "optimum use of space" are other important parametres with approximately similar scores.

In this regard, we can note that in the construction and design of the studied bazaars, four elements including "compatibility with the urban environment", "creativity and diversity in designing and constructing", "multi functional spaces" and "appropriate divisions and specific details of spaces" with similar average scores (all less than average score of 3), are not acceptable in terms of citizens' points of view in designing and constructing the mentioned bazaars.

Also, based on the observations in this work, in Tajrish bazaar, low level natural lighting, inappropriate space divisions, narrow corridors and insufficient seating areas for citizens were perceivable. In Rey bazaar, monotonous spaces have reduced attractions for users, while Almas shopping centre was experiencing lack of natural lighting in the interior spaces, and improper combination of internal and external environment. In Tirajheh shopping centre, the divisions of the interior spaces and utilization of natural lighting were improper.

From analysing the participants' suggestions, it can be observed that the most important principle from citizens' point of view is "recyclable materials". This observation means that citizens expect to use the material in the construction of business spaces that could be easily released into nature during the destruction time. One reason that recyclable material is the most important factor for the users is their opinion about eco-friendly architecture and the importance of materials. The second suggestion of the participants is to pay attention to natural lighting and its properties. This is because of the values and special considerations that were given to the natural lighting in the traditional architecture.

Based on the responses to the suggestions, designing open spaces inspired by Iranian traditional architecture has the lowest level of the citizens' willingness. This situation means that users prefer applying the concepts to the repeated use of traditional architectural elements. In general, however, it is observed that except for the mentioned question, the answer to all suggestions has an acceptable average score, which requires special attention in designing future bazaars.

Table 2 presents the central distribution statistics of the study. All variables are reported higher than the average of the society (3).

Table 2. Central Distribution Statistics of Variables

\begin{tabular}{lcc}
\hline Variable & Mean & Standard Deviation \\
\hline Nature and tradition & $3 / 05$ & $0 / 533$ \\
Suggestions & $3 / 66$ & $0 / 655$ \\
\hline
\end{tabular}



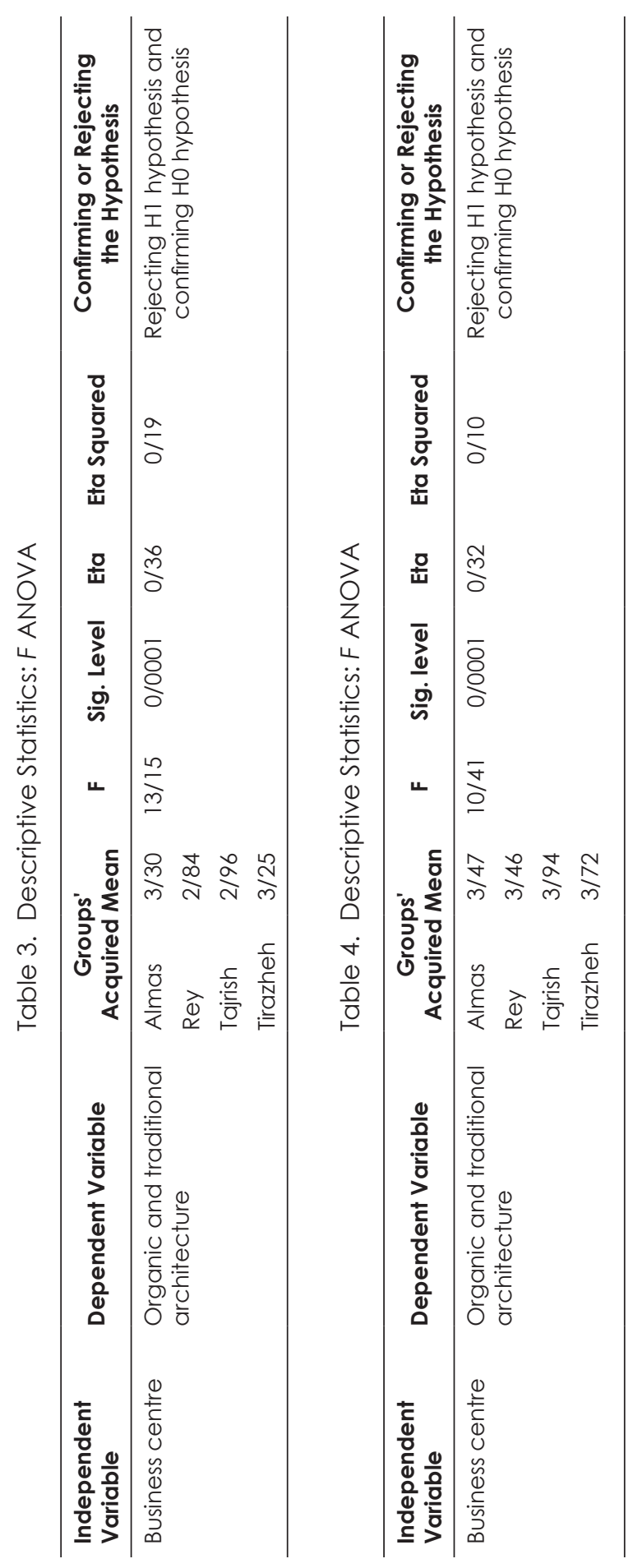

PENERBIT UNIVERSITI SAINS MALAYSIA/161 
The average score of the first part (attention to traditional architecture and naturalism in bazaars) with a score close to the average cannot explain the proposed indicators ideally in the questionnaire of the study. This sisis due to the lack of sheer satisfaction of the users from the available business centres. Suggestions section with a higher average score from the citizens' viewpoint is notable. This means that according to the tastes of the community, the bazaar's design can be more functional and more adaptable.

According to the tests in Table 3, because the sig. amount in ANOVA table is less than 0.05 (i.e. 0.0001 ), this hypothesis is confirmed. It is concluded that there is a significant difference among the users' suggestions in four business complexes. Almas with an average score of 3.30 has the highest rate. Tirazheh, Tajish and Rey have the scores of 3.25, 2.96 and 2.84, respectively. Moreover, the Eta coefficient in the Eta table is 0.36 that reports a moderate intensity of relationship between the two variables. The Eta squared also indicates that only $0.19 \%$ of the dependent variance (organic architecture) could be explained with the variance of the independent variable (traditional architecture). This result means that in the studied bazaars there is a moderate level of relationship between traditional architecture and organic architecture. Therefore, the number 0.36 shows that the relationship between the concepts is moderate.

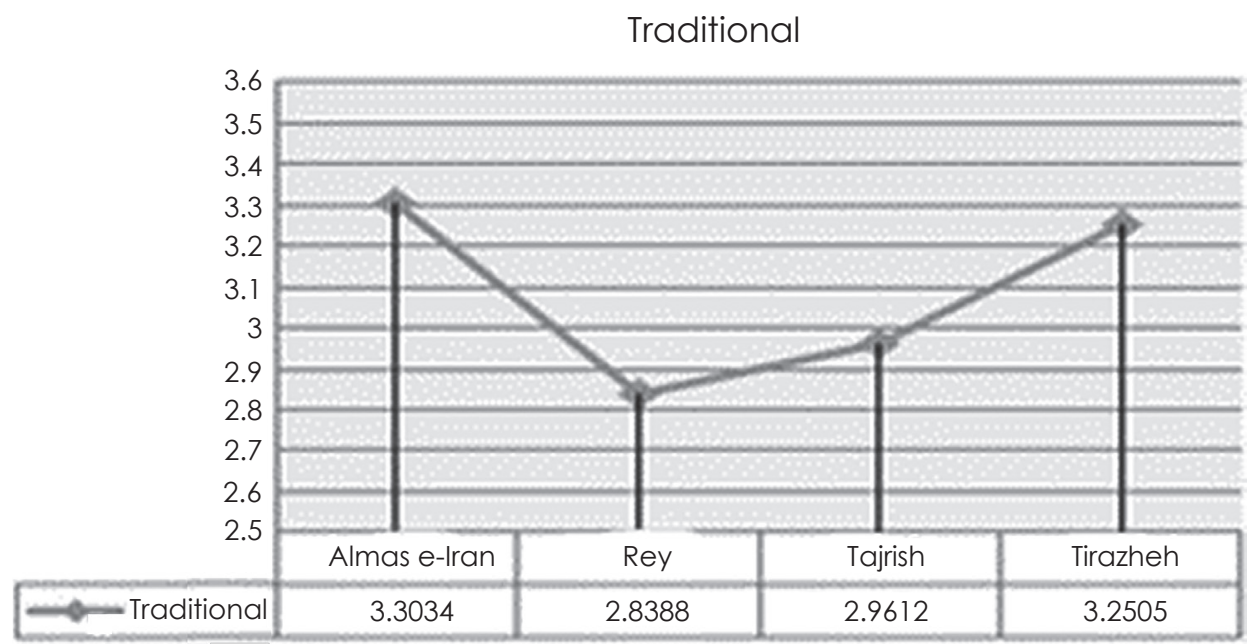

Figure 8. Descriptive Statistics: Average Acquired Relationship between Nature and Tradition

Table 3 and Figure 9 represent the citizens' responses in the analysis of the studied bazaars separately. Based on the above table and graph, it can be seen that despite their traditional designs, both Rey and Tajrish bazaars cannot gain the average characteristics. However, Tirazheh and Almas bazaars, which have modern designs, gained higher scores than the average of 3 . The reason is that although the principles measured in this study is represented in structural appearance of Tajish and Rey bazaars, the same principles are not perceptible to individuals from, psychological aspect and the feelings that they receive from the 
environment. In this respect, it is perceivable that Tirzheh and Almas look modern and do not reflect traditional architecture and nature-oriented architecture in their appearances. What they bring in the minds of citizens and what is reflected from the spaces of these bazaars can significantly contain the principles questioned in this study. Another reason is that despite the attentions of the participants to the traditional architecture, current users want the presentation of these elements in a modern way.

\section{Suggestions}

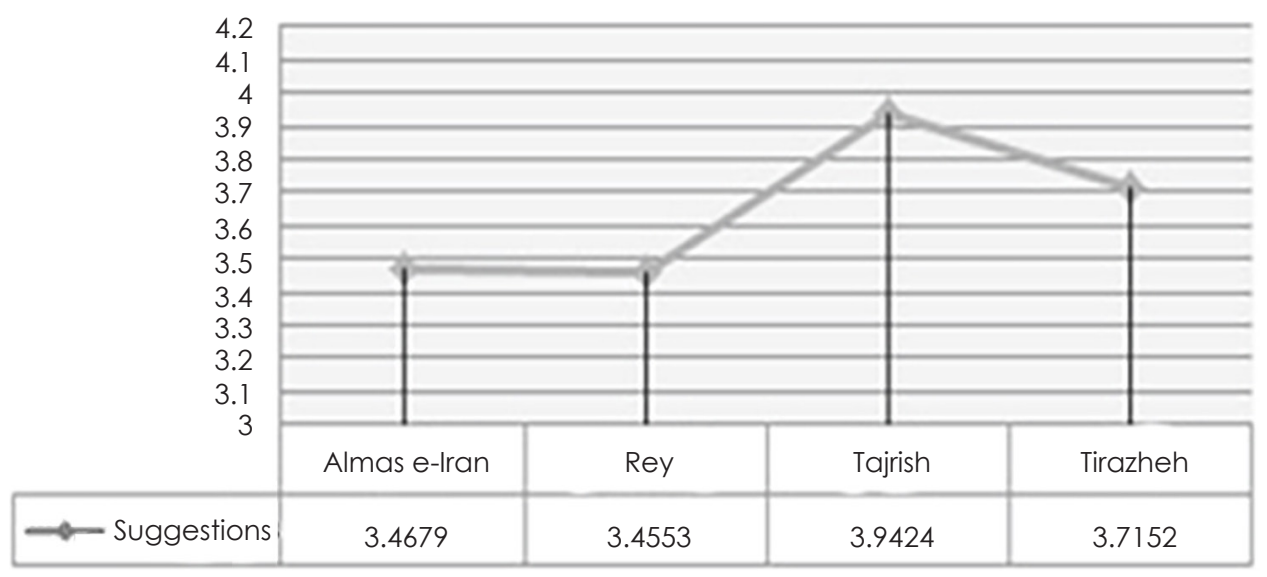

Figure 9. Average Acquisition of Suggestions on Samples

\section{CONCLUSION}

Iranian traditional architecture was in harmony with people and their environment. According to the results from this study, despite the sheer traditional face and appearance of Tajish and Rey bazaars, in participants' opinions, these places did not have the traditional architectural features and naturalism that were asked in this study. Thus, it is concluded that having mere similarity of an environment or body to one element or concept cannot represent the considered criteria for the users. In other words, individuals will pay attention to psychological and subjective features of elements as well as the visual and physical aspects of a space. For instance, probably we would not design the principles and requirements of Iranians bazaars' passageways (Timcheh) in modern bazaars, however we would definitely recreate its spirit by using various techniques. The results also showed that an Iranian citizen pays more attention to the nature-oriented architecture that is distinct and directly related to the traditional architecture. It is suggested that designers pay special attention to this section of their interests. For example, it was observed that the participants pay much attention to the usage of the recyclable materials, natural lighting, water and Iranian architectural geometry retrieved from the existing elements in the nature. 


\section{REFERENCES}

AoA (2011). Bazaar in Iran. Online Journal of Art and Architecture, 21: 106.

Ashraf, M. (2009). CDS a new approach in urban planning in a analytical approach. Quarterly of Urban Management, 23.

Assari, A., Mahesh, T.M., Emtehani, M.R. and Assari, E. (2011). Comparative sustainability of bazaar in Iranian traditional cities: Case studies in isfahan and Tabriz. International Journal on Technical and Physical Problems of Engineering (IJTPE), 9(3): 18-24.

Azad, M. (2006). Identity crisis and the lack of traditional patterns in contemporary architecture in Iran. Abadi Journal, 17(52): 34-39.

Carmona, M., Tiesdell, S., Heath, T. and Oc, T. (2003). Public Places: Urban Spaces. London: Architectural Press.

Ebrahimi, S. and Eslami, G. (1991). About urbanism and traditional architecture of Iran. Hoviate Shahr, 6(4): 3-14.

Ekhlas, M. (2013). Search in deep traditional architectural structures with emphasis on architecture of Iran's Grand Bazaar space body. Paper presented at the First National Conference on Geography, Urban Development and Sustainability. Tehran, Iran.

Falahat, M. and Shahidi, S. (2003). The evolution of nature and its role in the formation of architectural space. Fine Arts Journal, 42(2): 37-46.

Falamaki, M.M., (2006). Restoration of Iran's Monuments and Historical Cities. Tehran: Tehran University Publication, 215-216.

Faqani, A. (2006). Treasures of history of Rey. Resalat Paper No. 5888. n.p., 5-6.

Golan, G. (1995). Ethics and Urban Design. New York: John Wiley and Sons, 117-1 18.

Mohammadi, S.N. (2009). The necessity to understand the nature of space -based architecture based on contemporary approaches to nature. Fine Arts Journal, 37(1): 49-58.

Moosavi, M.S. (2005). Bazaar and its role in the development of Iranian traditional cities. Paper presented at the 2005 IRCICA International Conference of Islamic Archaeology.

Moradi, A.M. and Akhtarkavan, M. (2008). Sustainable architecture in the hot, arid and sunny regions of Iran. IUST International Journal of Engineering Science, Architect Engineering Special Issue, 19(6): 21-29.

Moradi, A.M., Kooshesh-Garan, S.A.A. and Akhtarkavan, M. (2011). An introduction to the way of regarding the Earth (site) in traditional architecture: Recognition of the architect's attitude toward Earth in the traditional era. International Journal of Architectural Engineering and Urban Planning, 21 (1): 28-34.

Nezhad, J.M., Sabri, R.S., Damvandi, M., Pour E.A. and Asadolah, J. (2012). Architectural design with an emphasis on interactivity and beauty. Hoviate Shahr, 10(6): 59-66.

Nouri M. (2014). A comparative study of design principles in the architectural styles associated with sustainability and sustainable development. Journal of Art and Architecture Studies (JAAS), 3(1): 46-52.

Parast, M.M. (1999). Sustainable architecture in the desert like cities in Iran. Arman Shahr Journal, 3(2): 121-128.

Pirniya, K. (2010). Introduction to Islamic Architecture. Tehran: Soroush Publication.

Sanei, H. (1990). What happened to the Iranian traditional architecture. Sakhtaman, 16(1): 26-32. 
Saremi, A.A. and Radmehr, T. (1997). The Lasting Values in Iran's Architecture. Tehran: Cultural Heritage, 78.

Scott, A. (2000). Dimensions of Sustainability. London: E \& FN Spon.

Sodkhah, E. and Qaleh, J.K. (2013). Recognizing the evolution of the market space body in Iran. Paper presented at the First Conference on Architecture, Restoration of Urban Development and Environmental Sustainability. Hamedan, Iran.

Talebian, N., Atashi, M. and Zadeh, S.N. (2010). Commercial Buildings. Tehran: Herfeh Honarmand Publication.

Taqvai, V. (2007). Hidden space system of Iranian architecture and its structure. Fine Arts Journal, 30(1): 43-52. 